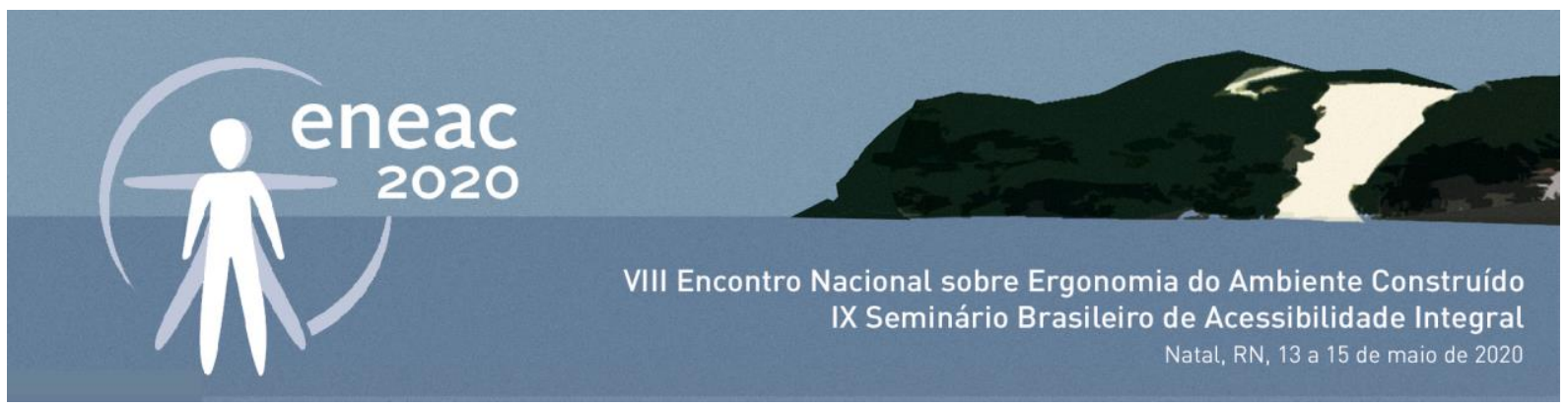

\title{
Notas sobre prioridades de melhoria da acessibilidade na revisão do Plano Diretor de Natal
}

\author{
Notes on accessibility improvement priorities in the revision of Natal \\ City Master Plan
}

SAULO MATHEUS DE OLIVEIRA LIMA CAVALCANTE

Bacharel, mestrando no PPGAU-UFRN, saul.om@hotmail.com

RICARDO DE SOUSA MORETTI

Doutor, professor visitante do Departamento de Arquitetura da UFRN, ufrn.moretti@gmail.com

\section{RESUMO}

$\mathrm{O}$ artigo analisa algumas contradições estruturais verificadas no patrimônio edificado e no sistema viário públicos, em termos de planejamento, projeto, obras e manutenção, que trazem dificuldades para a melhoria da acessibilidade. A partir desta reflexão, é apresentado o contexto da revisão do Plano Diretor de Natal, em curso, são apontadas algumas situações verificadas ao longo do território do município em que é comprometida a acessibilidade de pessoas com deficiência e com mobilidade reduzida e são analisadas algumas prioridades para inclusão no plano, na perspectiva de um embasamento institucional para melhoria da acessibilidade na cidade. A hipótese é que a legislação, em especial o Plano Diretor, pode ser uma alavanca para superar algumas das condições estruturais que dificultam a melhoria da acessibilidade. Nesse sentido, são indicados apontamentos a serem incorporados ao plano como norteadores de uma mudança da realidade verificada nos espaços públicos e privados a partir da intervenção do planejamento urbano e de uma reestruturação de organização da gestão desses espaços.

PALAVRAS-CHAVE: Acessibilidade urbana, plano diretor, planejamento urbano

\begin{abstract}
The paper discusses some structural contradictions seen in public circulation system and in the built heritage, in planning, project and maintenance phases, that bring problems to accessibility. Based on this, it is presented the context of Natal City Master Plan revision and some situations where the accessibility is blocked for those with mobility limitations, and then, some priorities to be included in the Master Plan. The hypothesis is that the legislation, specially the Master Plan, can be an important support to overcome some structural conditions that avoid accessibility improvement actions. The suggestion of topics to be included in the Master Plan aims changes in public and private spaces through urban planning and through the reorganization of the management of theses spaces.
\end{abstract}

KEYWORDS: urban accessibility, master plan, urban planning. 


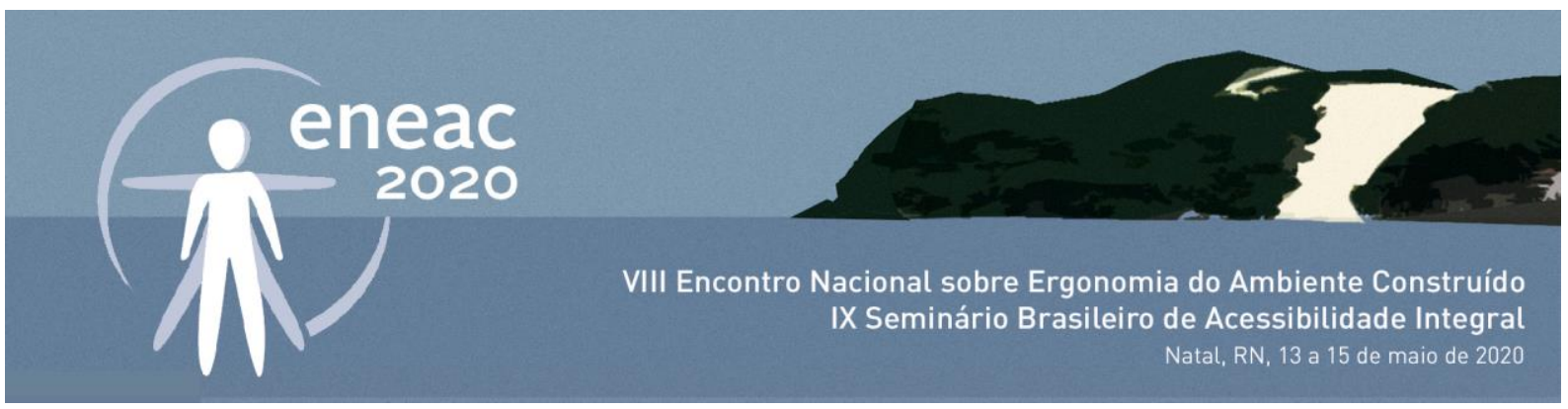

\section{INTRODUÇÃO}

A revisão do Plano Diretor do Município de Natal (PDN), no Rio Grande do Norte foi oficialmente deflagrado em 2017, mas a fase das oficinas de participação popular passou a acontecer apenas no segundo semestre de 2019. Esperava-se que temas relativos aos problemas enfrentados pela cidade fossem profundamente debatidos, porém, até o momento, vivencia-se um processo com limitada participação social, abordagem superficial da realidade urbana do seu território e concentração da discussão em torno das pautas mais caras aos setores especulativo-imobiliários. Os debates sobre controle de gabarito, coeficientes de aproveitamento e parâmetros urbanísticos associados, pairam e eclipsam a discussão dos problemas que diretamente incidem sobre a população mais vulnerável e sobre os grupos sociais que mais carecem de uma cidade mais inclusiva e acessível. Dentre esse rol, estão as questões relativas à livre circulação de pessoas com deficiência (PCDs) e/ou com mobilidade reduzida (PMRs).

Figura 1 Escada de acesso à faixa de areia da Praia de Ponta Negra

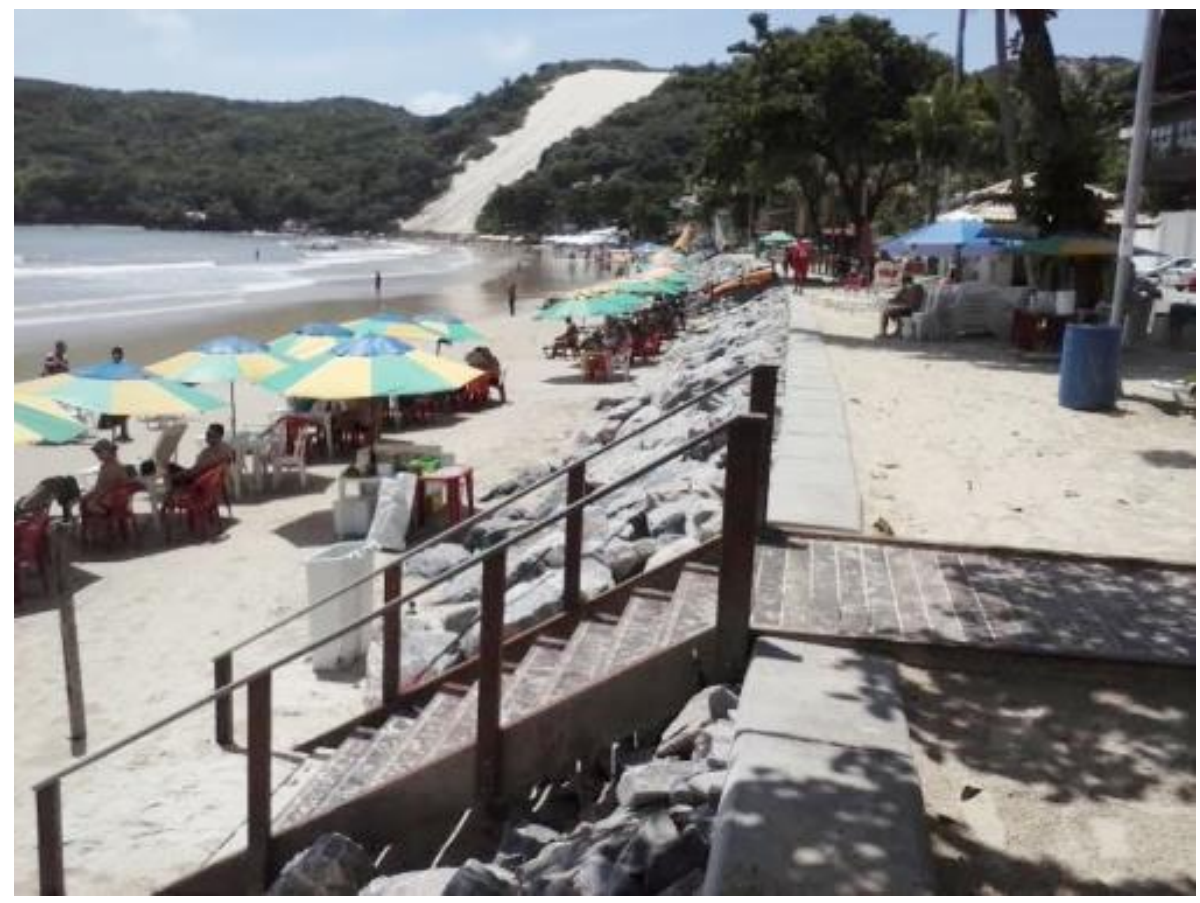

Fonte: CAVALCANTE, 2019

Enquanto o chefe Poder Executivo Municipal, em seus pronunciamentos e atos públicos, confessa sua reiterada defesa pelo aumento da verticalização na orla marítima e pela concessão de maiores potenciais construtivos aos bairros mais nobres, a orla carece de qualificação urbanística que permita o acesso de PCDs e PMRs às faixas de areia e ao mar, bem como os passeios públicos da cidade carecem de padronização e adequação às normas de acessibilidade. Na maioria dos trechos das praias urbanas não há sequer rampas que permitam o acesso à praia, restringindo, numa lógica 


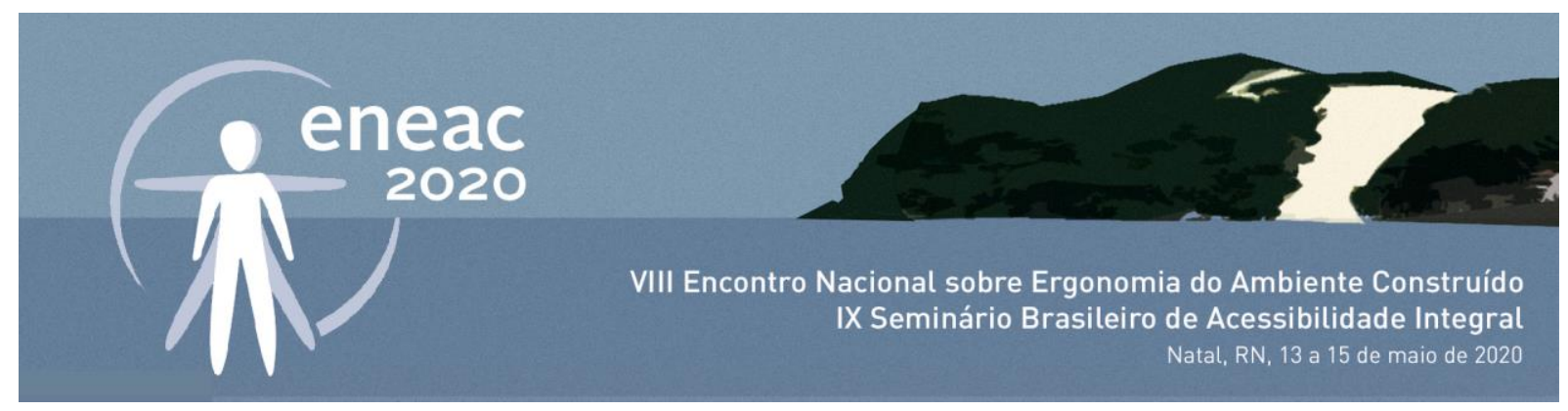

capacitista, o uso desse importante espaço de lazer a uma parcela da sociedade. Na praia que abriga o maior cartão-postal da cidade, o Morro do Careca, em Ponta Negra, graças à força do mar contra o calçadão mal executado, foram destruídos os acessos em alvenaria e, atualmente, para se chegar à faixa de areia, como ilustra a figura 1, é necessário transpor escadas de madeira, as quais estão também em desconformidade à Norma brasileira de acessibilidade a edificações, mobiliário, espaços e equipamentos urbanos, a NBR 9050-2015, (ASSOCIAÇÃO BRASILEIRA DE NORMAS TÉCNICAS, 2015).

O quadro normativo urbanístico de Natal abarca a temática da acessibilidade desde 1992, quando foi sancionada a Lei no 4.090, de 03 de julho de 1992, que trata da eliminação de barreiras arquitetônicas nos locais de fluxo de pedestres (NATAL, 1992). O referido instrumento, estabelece regras e instruções para intervenção em tais espaços de forma pouco detalhada, mas sinaliza uma preocupação do Poder Público com a temática, o que foi ratificado na revisão do PDN em 2007, que está vigente. O Plano Diretor atual estabelece, como um dos critérios que asseguram o seu objetivo de pleno desenvolvimento das funções socioambientais da propriedade, a adequação dos espaços coletivos à acessibilidade urbana para todos os seus cidadãos (NATAL, 2007). Todavia, ao tratar diretamente dessa acessibilidade, o plano limita-se a dispor objetivos a serem cumpridos pela Política e pelo Plano Diretor de Mobilidade Urbana (NATAL, 2007). Dentro dessa perspectiva, observa-se a necessidade de discutir esse modelo, bem como outros aspectos legislativos e operacionais que impliquem nesse tema.

Entretanto, apesar de não constar na programação oficial de atividades previstas pela equipe de coordenação da revisão do PDN, ocorreu na Câmara Municipal de Natal uma reunião, promovida pela Comissão em Defesa dos Direitos das Pessoas com Deficiência e Mobilidade Reduzida, no dia 11 de setembro de 2019, em que foram debatidas possibilidades de melhoria da acessibilidade na cidade, ocasião em que foi possível debater também algumas contradições estruturais verificadas no patrimônio edificado e no sistema viário públicos, em termos de planejamento, projeto, obras e manutenção, que trazem dificuldades para a melhoria da acessibilidade. Essas contradições são aqui expostas e são apresentados os tópicos considerados estratégicos para serem incluídos no PDN, para enfrentar as dificuldades assinaladas.

\section{CONTRADIÇÕES DO PATRIMÔNIO EDIFICADO E SISTEMA VIÁRIO PÚBLICO COMO ENTRAVES PARA MELHORIA DA ACESSIBILIDADE}

\section{Passeios de pedestres tratados como espaços públicos de segunda grandeza}

Em grande parte das cidades brasileiras o passeio de pedestres é um espaço público tratado com desdém, como se não se tratasse de um efetivo bem de uso comum. Esse tratamento desigual se manifesta em múltiplas dimensões, entre eles incluída a transferência da responsabilidade pela execução e manutenção do calçamento aos proprietários dos imóveis lindeiros. Em Natal, cada proprietário executa o calçamento com o material e com a geometria que considera adequada, seguindo um conjunto de regras que são fracamente cobradas e fiscalizadas.

A execução de rampas para acesso aos lotes é usualmente feita com sua concordância na área pública do passeio de pedestres, tirando assim a continuidade necessária para a circulação de cadeiras de rodas, carrinhos de bebê e constituindo, em alguns casos, um verdadeiro obstáculo para utilização do passeio como área de circulação. Não é difícil encontrar no passeio de uma mesma quadra, um 


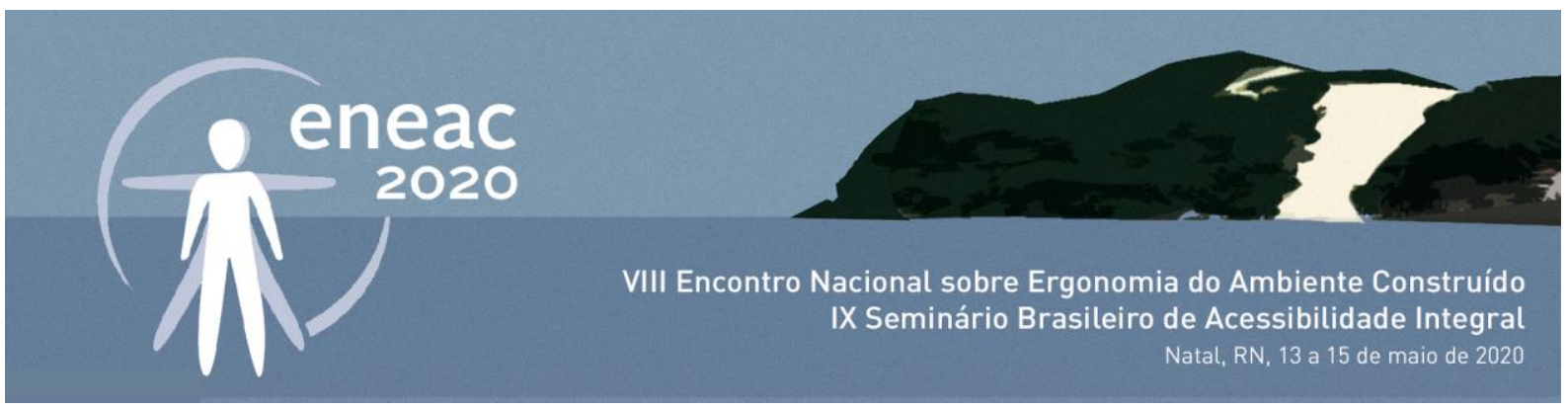

calçamento executado com grama, outro trecho com granito polido, trazendo sérios riscos nos dias de chuva, e outro trecho em que simplesmente não há calçamento, junto a um lote desocupado.

Há reclamação contundente quando a pista de rolamento, onde circulam os veículos automotores, apresenta buracos ou outro tipo de descontinuidade. Mas infelizmente considera-se usual e corriqueiro que não haja continuidade ou condição de uso do passeio de pedestres e que estes sejam obrigados a disputar o espaço com os carros na pista de rolamento.

Outro problema é a naturalidade como o particular se apropria ilegalmente do espaço público do passeio de pedestres, sem que haja uma reação popular ou do poder público, como pode ser visto nas figuras 2 e 3, o que ilustra, infelizmente, a tese apresentada neste tópico de que o espaço do pedestre é considerado, na prática, pelos cidadãos e também pelo poder público, como um espaço público de segunda grandeza, de menor importância. Considera-se que a reversão desta tendência é chave estratégica para melhorar a acessibilidade nas nossas cidades.

Figura 2: Os passeios de pedestres em ambos os lados da via são usados como estacionamento por frequentadores de uma escola privada no bairro de Tirol em Natal. Notar a ironia da inclusão do piso tátil para cegos, no calçamento do passeio.

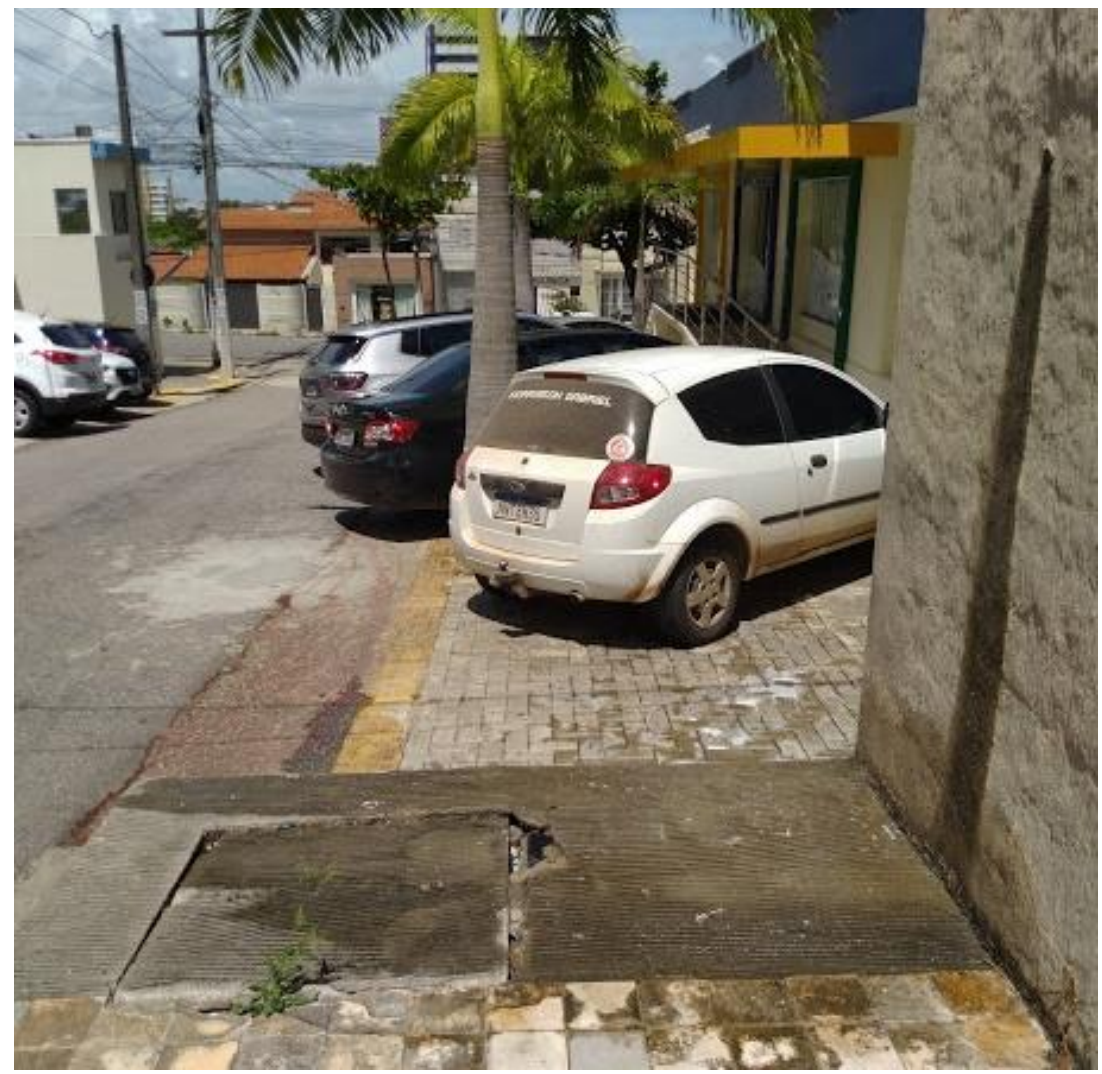

Fonte: MORETTI, 2019 


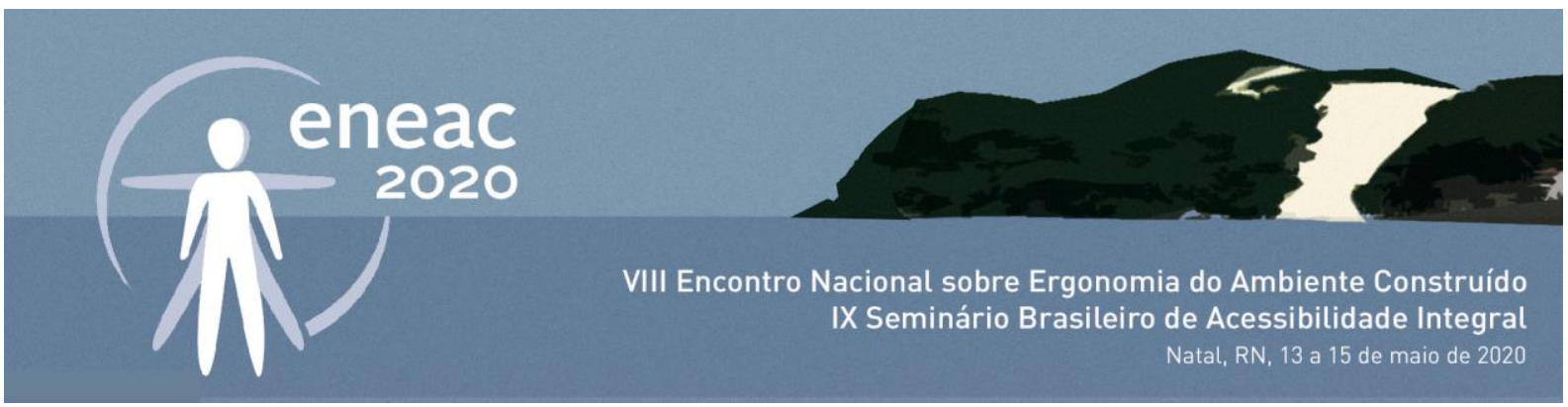

Figura 3: O muro reformado viabiliza que os automóveis utilizem o passeio de pedestres como estacionamento, em uma avenida do bairro nobre do Tirol, em Natal.

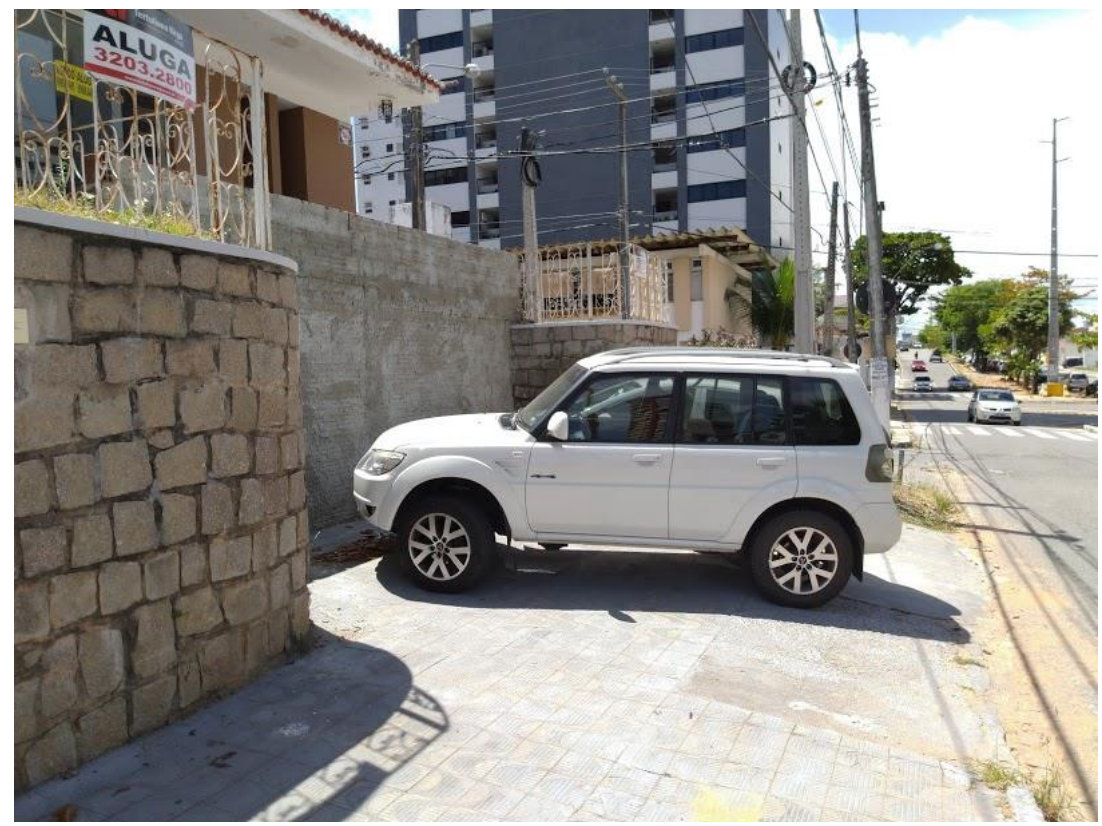

Fonte: MORETTI, 2019

\section{Ausência de uma orquestração pública para as intervenções feitas no sistema viário}

Existem, em algumas cidades, mais que uma dezena de diferentes órgãos, públicos e privados, que executam planos, projetos e obras no sistema viário público. Entre outros, incluem-se as companhias de saneamento, eletricidade, gás, telefonia e os órgãos que cuidam da sinalização de tráfego, iluminação pública, arborização, mobiliário urbano, engenharia de tráfego, além evidentemente dos proprietários dos terrenos que executam o calçamento dos passeios e o órgão municipal que executa o calçamento da pista de rolamento.

É rara a existência sequer de um cadastro das obras já implantadas no sistema viário público. Cada órgão executa seus planos, projetos e obras de acordo com suas prioridades e com aquilo que otimiza seus objetivos, sem considerar o conjunto. Assim, os conflitos são inevitáveis: árvores que impedem a iluminação ou a visibilidade das placas de trânsito, equipamentos que impedem a adequada circulação de pedestres e uma dificuldade extrema em qualquer obra subterrânea, por não se saber o que haverá no trajeto.

A situação, grosso modo, pode ser comparada a uma orquestra, em que cada músico, com grande maestria, toca sua própria partitura. O controle público sobre os planos, projetos e obras que se executam no sistema viário público, de forma orquestrada, pode ser considerada também outro eixo estratégico para que se possa efetivamente avançar no sentido da melhoria da acessibilidade nas nossas cidades.

\section{Dificuldades de acessibilidade nos prédios públicos e no seu entorno}




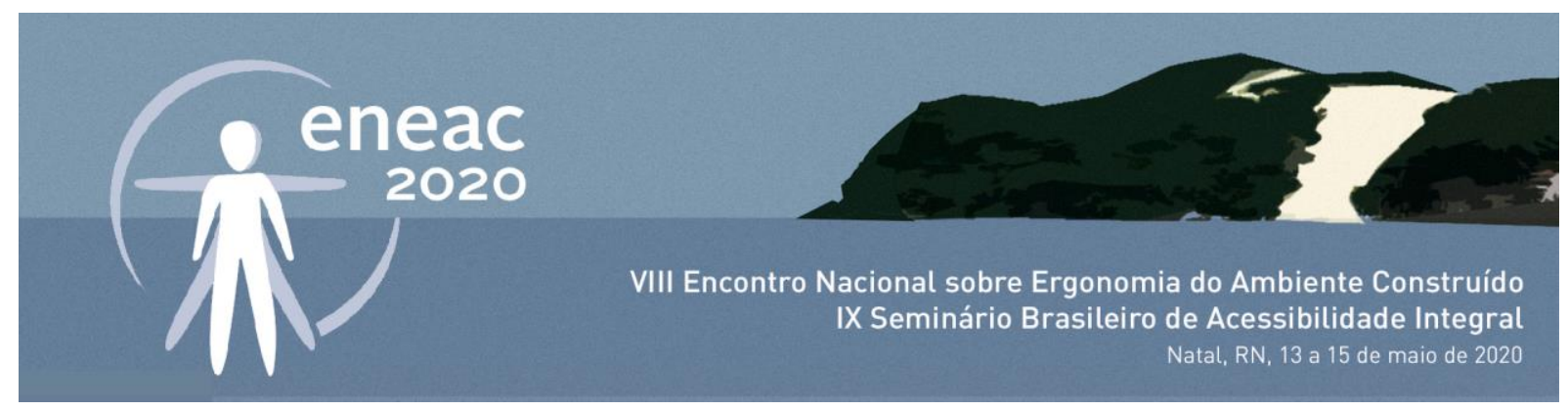

Apesar do Brasil ser um país com urbanização relativamente recente, há um patrimônio público edificado, relativamente grande, que foi executado quando não havia ainda a preocupação em garantir o desenho universal e a acessibilidade. O mesmo acontece com os espaços públicos no entorno destes prédios, que nem sempre permitem a circulação de cadeirantes e outras pessoas com dificuldade de mobilidade. Os marcos normativos que exigem adoção de medidas para tal garantia são relativamente recentes e não há apropriação adequada por parte de profissionais e órgãos públicos de suas exigências, o que dificulta ainda mais a efetividade dessas leis. Porém, é importante que sejam os edifícios públicos, voltados ao atendimento à população e de responsabilidade do Poder Público, que devam melhor dotar-se de meios de adequar-se às normas e garantir a universalização do seu acesso.

Entende-se que assegurar a acessibilidade em todos os prédios públicos e no seu entorno imediato, é uma intervenção que não se consegue de pronto, mas a melhoria gradativa da acessibilidade nesses edifícios deve ser uma das prioridades de um planejamento voltado para a melhoria geral de acessibilidade em uma cidade.

\section{Novas edificações particulares não atendem parâmetros mínimos do desenho universal}

A universalização da acessibilidade pressupõe uma gradativa implementação dos princípios do desenho universal que viabilize condições de acesso para quem tem mobilidade reduzida a todos os espaços da cidade, sejam eles públicos ou privados. Se a adequação do patrimônio edificado público já constitui um grande desafio, como apontado no tópico anterior, a adequação do patrimônio privado constitui um desafio maior ainda. Porém, da mesma forma que não se justifica a construção de um novo prédio público que não atenda às regras construtivas que asseguram acessibilidade, entende-se que é coerente que se exija, também das novas edificações particulares, o atendimento de alguns parâmetros do desenho universal, para que seja mais fácil e rápida a transição para uma situação de plena acessibilidade.

Ainda que se entenda a importância de garantir a adequação de todos os espaços para PCDs e PMRs, as legislações e normas técnicas não abarcam tal exigência a todas as edificações, como cita a NBR9050:

As edificações residenciais multifamiliares, condomínios e conjuntos habitacionais necessitam ser acessíveis em suas áreas de uso comum. As unidades autônomas acessíveis são localizadas em rota acessível (ASSOCIAÇÃO BRASILEIRA DE NORMAS TÉCNICAS, 2015, p. 1).

Como exemplo, considera-se uma incoerência permitir que, em um edifício residencial novo, sejam utilizadas portas com vão livre inferior a $80 \mathrm{~cm}$ de largura. Pois, a qualquer momento o morador pode ser forçado a utilizar, mesmo que temporariamente, uma cadeira de rodas e o vão da porta vai constituir um obstáculo praticamente intransponível nesse sentido. Da mesma forma, mesmo que seja aceita a construção de um prédio sem elevadores, há que se exigir que a geometria do projeto preveja e indique o local onde poderá no futuro ser implantado esse equipamento. Ou seja, é fundamental que as novas construções particulares tenham condições geométricas para atender a acessibilidade, mesmo que nem todos os equipamentos e parâmetros sejam atendidos de imediato.

\section{PRIORIDADES PARA INCLUSÃO NO PLANO DIRETOR}

Evidentemente, as contradições aqui apontadas não poderão ser plenamente equacionadas através 


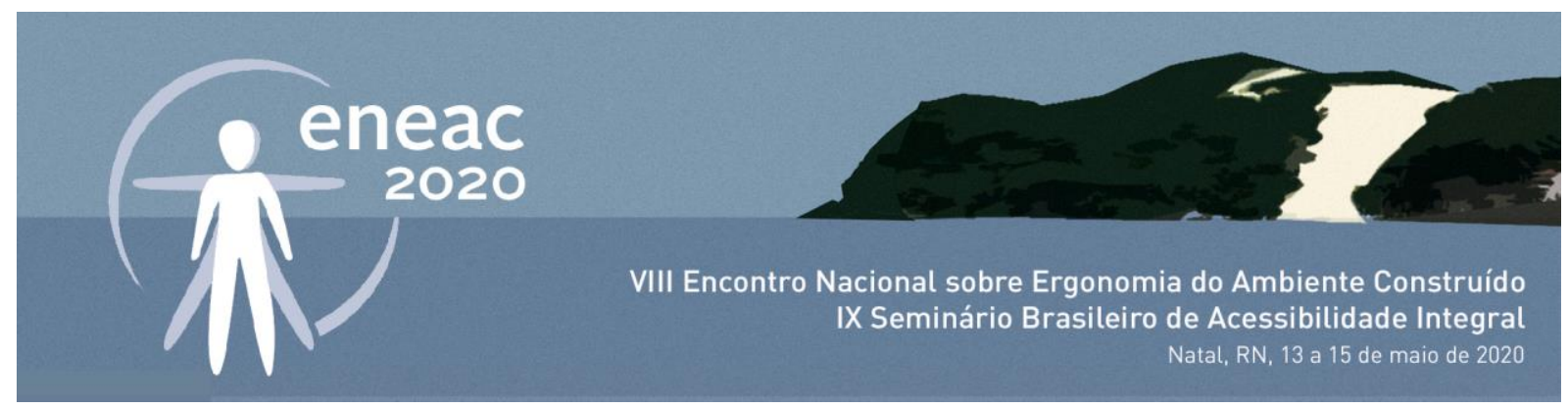

exclusivamente da legislação, aí incluindo-se o Plano Diretor. Em alguns casos a legislação até já existe, mas não é cumprida, por motivos culturais, ou seja, a norma não consegue modificar uma visão que se enraizou na sociedade. A transformação destes conceitos prévios, enraizados, é um processo muitas vezes lento, mas viável. Basta lembrar a proibição de fumar nos aviões, salas de aula ou espaços de uso público fechados. Ou ainda a obrigatoriedade de utilizar o cinto de segurança. E nesse processo gradual de transformação, a legislação pode cumprir um papel importante.

Quando se analisa especificamente o Plano Diretor, e se considera esse instrumento como sendo o estruturador e organizador de planos e programas que a população sonha ver implementados, chegase à conclusão que é muito importante que ele sinalize algumas iniciativas que vão na direção da gradativa conquista da acessibilidade na cidade.

Alguns tópicos já estão inclusive regulamentados, como por exemplo, a exigência legal de que os Planos Diretores municipais explicitem as rotas acessíveis na cidade. Mas há outras possibilidades. No campo institucional, o plano, por ser o instrumento básico da política de desenvolvimento e expansão urbana (BRASIL, 1988), pode prever a criação de organismos ou instituições com responsabilidades específicas. Pode explicitar a necessidade do desenvolvimento de um programa, plano ou projeto. E pode ainda sinalizar orientações que serão detalhadas em outras legislações, como por exemplo, na Lei de Parcelamento do Solo, Código de Obras ou de Posturas.

Frente às contradições anteriormente apontadas, identificam-se alguns tópicos que poderiam ser incluídos no Plano Diretor de Natal, por ocasião da sua revisão, que está em curso.

Entre eles destacam-se:

a- A criação de um órgão ou instituição na administração municipal para orquestrar os planos, programas, projetos e obras que são executados no sistema viário público. Essa instituição, entre outras atribuições, ficaria encarregada de acolher, analisar e cadastrar todas as atividades, projetos e obras que são propostas para o sistema viário público.

b- Explicitação da exigência de execução do calçamento dos passeios públicos (calçadas) em todas as obras de pavimentação das pistas de rolamento do sistema viário público. Exigência neste sentido já consta dos casos de obras executadas com recursos do governo federal e a indicação no PD ampliaria o escopo desta medida para toda pavimentação feita na cidade, com recursos do loteador ou do poder público municipal;

c- Incluir entre as rotas acessíveis a serem delimitadas no Plano Diretor as calçadas do perímetro completo das quadras onde se inserem os equipamentos públicos das três esferas de governo.

d- Incluir a exigência de que, num prazo de um ano, cada órgão da administração pública municipal apresente um plano de adaptação dos imóveis sob sua responsabilidade, de forma a assegurar o gradativo avanço nas condições de acessibilidade, prevendo-se o atendimento à exigência da legislação de acessibilidade em um prazo máximo de 4 anos. Esse plano deverá apresentar as metas a serem atendidas ao final do primeiro, segundo e terceiro ano.

e- Explicitar a exigência de que toda nova edificação residencial a ser licenciada no município contemple as dimensões necessárias para a acessibilidade, contemplando os princípios do desenho universal, incluindo previsão de localização de elevador nos casos em que eles não serão executados em um primeiro momento e previsão de dimensões mínimas de banheiros, corredores, vãos de portas, entre outros, para assegurar os princípios de acessibilidade de pessoas com deficiência ou 


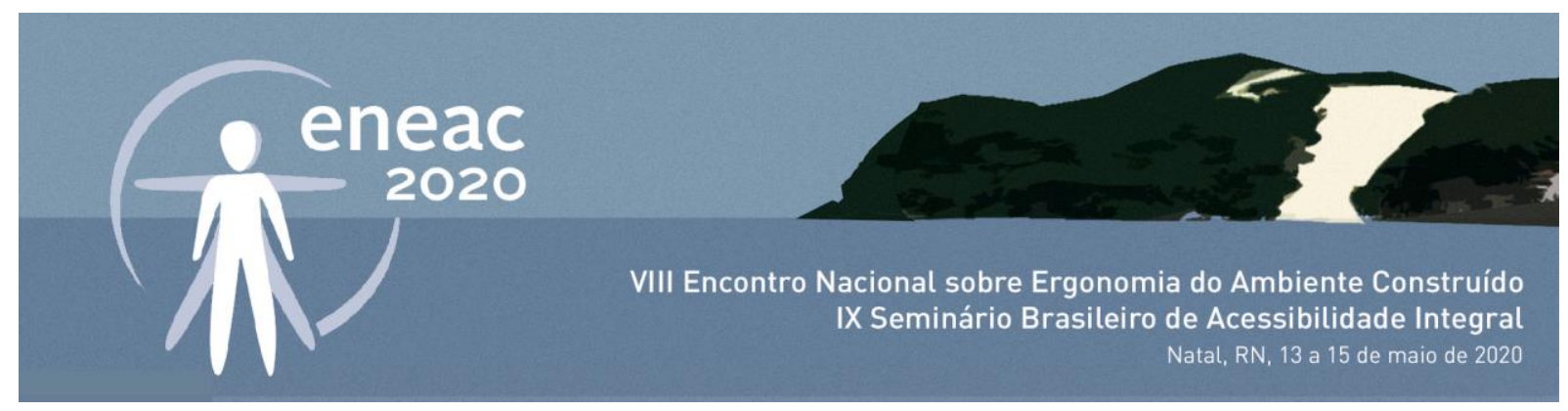

mobilidade reduzida.

f- Incluir a exigência de elaboração, no prazo máximo de um ano, de um plano de melhoria gradativa das calçadas já existentes no município, prevendo-se a meta de qualificação plena em um prazo máximo de 10 anos, prevendo-se a possibilidade de que o município possa executar obras de melhoria e reforma dos calçamentos dos passeios, ou de complementação de trechos ainda não executados, com cobrança dos proprietários lindeiros, quando for o caso.

\section{CONSIDERAÇÕES FINAIS}

Pode-se dizer que a superação dos obstáculos aqui apontados para melhoria da acessibilidade nas cidades brasileiras depende, primeiramente, de uma iniciativa do poder público, mas depende ainda de um engajamento mais amplo da sociedade. Como exemplo, para o funcionamento de um organismo que orquestre as ações no espaço viário público, é necessário que ocorra a sua criação. É um passo inicial fundamental. Mas, para que sua ação seja efetiva, é necessário também o entendimento mais amplo da importância estratégica desta iniciativa para que órgãos privados e públicos de diferentes níveis federativos decidam submeter-se a um entendimento comum sobre as intervenções no espaço que é de todos. Ou seja, o esforço legislativo é necessário, mas isoladamente não é suficiente.

Cumpre analisar as estratégias que estiveram envolvidas em algumas mudanças de hábito que se concretizaram no país, como por exemplo, o atendimento à prioridade à travessia de pedestres nas faixas de pedestres, que se tornou real em alguns locais, como por exemplo no Distrito Federal. Ou ainda a incorporação do hábito de utilização do cinto de segurança, em especial no banco dianteiro. Vale destacar que, nestes casos houve um esforço de regulamentação legislativa, mas ele foi acompanhado de campanhas de esclarecimento e orientação, bem como de uma ação contundente de fiscalização e punição, após um período em que a tônica foi o esclarecimento.

Entende-se que a inclusão, na pauta urbana, da prioridade da acessibilidade para todos é um processo. E o processo público de debates que acompanha a revisão do Plano Diretor de Natal poderia ser um componente importante nessa transição. Ou seja, o próprio processo de debate é um complemento para a regulamentação que nele estará contida.

\section{REFERÊNCIAS}

ASSOCIAÇÃO BRASILEIRA DE NORMAS TÉCNICAS. NBR 9050: Acessibilidade a edificações, mobiliário, espaços e equipamentos urbanos. Rio de Janeiro. 2015.

BRASIL. Constituição da República Federativa do Brasil de 1988. Planalto, 1988. Disponivel em: <http://www.planalto.gov.br/ccivil_03/Constituicao/Constituicao.htm>. Acesso em: 07 abr. 2019.

NATAL. LEI № 4.090, DE 03 DE JULHO DE 1992. Eliminação de barreiras arquitetônicas para portadores de deficiência nos locais de fluxo de pedestres e edifícios do uso público e dá outras providências, Natal, 03 Julho 1992. 


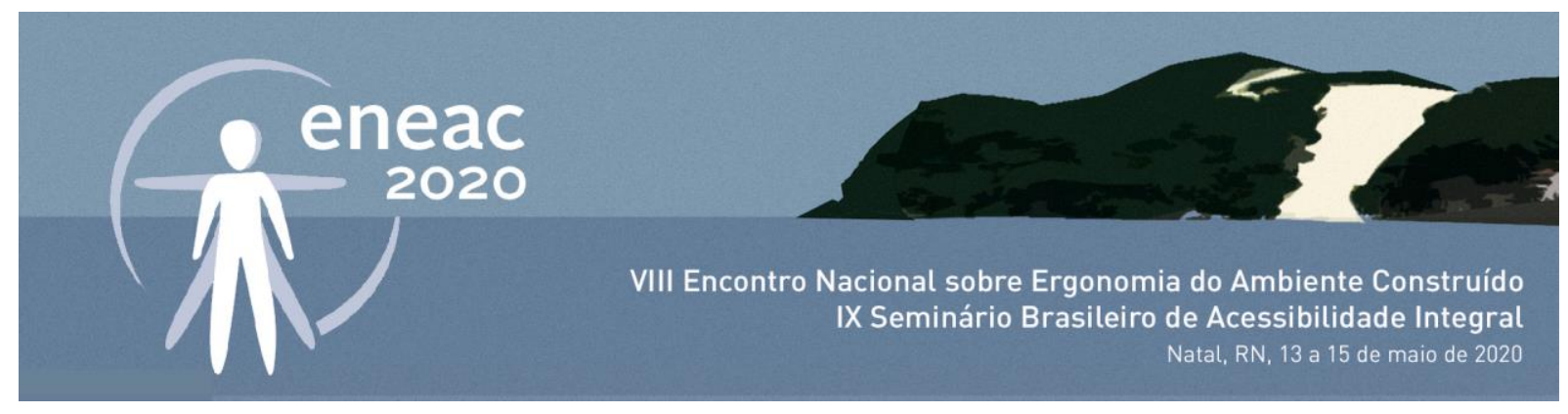

NATAL. Lei Complementar no 82, de 21 de jun. de 2007. Plano Diretor de Natal, Natal, RN, 21 Jun 2007. 6. 